\title{
Healthy diet social media campaign among Indonesian college students
}

\author{
Adella $^{1}$, Elisabeth Rukmini ${ }^{2}$ \\ ${ }^{1}$ Medical Education Unit, School of Medicine and Health Sciences, Atma Jaya Catholic University of Indonesia, \\ Indonesia \\ ${ }^{2}$ Department of Civil Engineering and Center for Urban Studies, Universitas Pembangunan Jaya, Indonesia
}

\section{Article Info}

Article history:

Received Jan 19, 2021

Revised May 12, 2021

Accepted Jun 16, 2021

\section{Keywords:}

Diet promotion

Healthy lifestyle

Instagram

Obesity prevention

Social media campaign

\begin{abstract}
Despite rise of self-perception towards eating balanced meals, obesity incidence remains high all over the world, reaching more than half billion people. It is worrisome since it leads to sedentary lifestyle that contributes to non-communicable diseases. Therefore, having adequate knowledge about healthy lifestyle, diet and eating habits from early age is crucial. Leveraging on the high usage of social media, educational intervention seems promising In this study, we assess the impact of using social media campaigns through Instagram to raise knowledge and encourage behavioral changes. Both quantitative and qualitative analyses were performed. Freshmen $(n=144)$ were selected as respondents and divided to two groups through random sampling. Those in intervention group received various information via Instagram for four months. All respondents had to fill self-administered knowledge questionnaires and food frequency questionnaire (FFQ) each month as evaluation. To evaluate the on-going campaign even more, we also collected qualitative data by interviewing respondents $(n=14)$. Data were analysed using constant comparative method (CCM). By the end of campaign period, there was only positive increasing trend in knowledge. Instagram was perceived as a suitable campaign media despite needing improvements. Overall, Instagram educational intervention had only successfully raised awareness and knowledge, not students' eating habits.
\end{abstract}

This is an open access article under the CC BY-SA license.

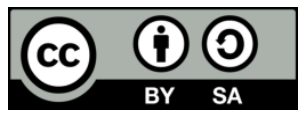

Corresponding Author:

Elisabeth Rukmini

Department of Civil Engineering and Center for Urban Studies

Universitas Pembangunan Jaya

Street Cendrawasih Raya Blok B7/P Bintaro Jaya, Sawah Baru, Ciputat, Tangerang South 15413, Indonesia

Email: Elisabeth.rukmini@upj.ac.id

\section{INTRODUCTION}

Nutritional awareness had gained more attention in the last few years. People start shifting to a healthier kind of diet [1]. A recent survey found that $65 \%$ of the population tried to cut down fat consumption and $62 \%$ on sweets. Moreover, $57 \%$ of the population had chosen to consume more natural fresh food [2]. However, this awareness did not reflect on lower obesity incidence [3]. Obesity remains one of the most neglected public health problems worldwide. The rate of obesity increases from 2.3 to $12 \%$ in the targeted population. Almost $30 \%$ of people categorized as overweight are the youth population, and a significant proportion of them are females. The increasing weight during youth in developing countries is approximately $1 \mathrm{~kg} /$ year higher than those in developed countries. A similar trend in Indonesia; overweight cases doubled up from 17.1 to $33 \%$ from 1993 to 2014 . Among youth, the incidence increased from $7.1 \%$ to $14.1 \%$ within the same period [4]. These high numbers are concerning as it led to sedentary lifestyle adaptation and higher 
chances of developing non-communicable diseases such as type II diabetes mellitus, dyslipidemia, coronary artery disease (CAD), sleep apnea, cognitive dysfunction, non-alcoholic fatty liver disease, and cancer in the future [5], [6]. A sedentary lifestyle itself is a way of living that encompasses less energy expenditure activities that have been adopted by $62.4 \%$ of the world's population nowadays [7]. This way of living also contributed to more non-communicable diseases (NCD) in society [8]-[10].

The vicious cycle between a sedentary lifestyle and obesity will lead to poor health outcomes. Therefore, an efficient prevention method in the early stage is necessary. Previous studies on a healthy diet and eating habits had identified some misconceptions. There is no consensus on what a healthy diet truly entails until today [11]. With various diet regimens offered, multiple cultural backgrounds, and beliefs, the public tends to get even more confused. A healthy diet is about adequate consumption of fruits and vegetables in which dietary patterns play a big part. It changes over time. The last couple of years had shown a decline in staple food consumption such as rice and other traditional food crops such as sweet potatoes, cassava, and pulses. However, this is not necessarily a good thing as the decline was followed by an increase in meat and wheat-based products consumption that brings detrimental side effects on the overall health condition [12], [13]. This situation raises the urgency to fix the misconception that is happening in our society nowadays [14]. Raising awareness and overall knowledge on healthy lifestyle, healthy diet, and eating habits become crucial. Researchers have conducted studies related to food choices, healthy diet, and eating habits among college students. The ample knowledge of a healthy diet was understandable [15]. However, awareness and practice were not in with the knowledge. Educational intervention through social media is one of the most substantial influences for university students due to their familiarity with social media [16].

Research on healthy diet promotion through social media has been encouraging toward the specific product of healthy food choices [17] or even to wider unspecific healthy diet promotion [18] or toward body image [19]. Research toward the impact of social media healthy diet on universities' students lacks evidence. Questions worth asking whether social media healthy diet campaign would be sufficient for college students. We administered a healthy diet social media campaign through Instagram. Visualizing the message will help college students understand quickly, and Instagram is the right choice for this visualization campaign. The healthy diet campaign through Instagram, including weekly messages within four months of intervention and self-assessment questionnaires.

This research aimed to assess social media campaigns' effectiveness in enhancing the awareness and overall knowledge of a healthy lifestyle, healthy diet, and eating habits. Secondly, we want to assess the extent of behavioural change towards adopting a healthy diet and eating habits at the end of the social media campaign period.

\section{RESEARCH METHOD}

This study was descriptive and exploratory research with a mixed-method approach.

\subsection{Quantitative method}

Quantitative data were collected from surveys using questionnaires. Participants of this study were first-year students of a medium-sized university in Jakarta that owned smart phone and active Instagram account. Those who had medical problems that required them to avoid particular food and/or beverages were excluded. Total of 144 participants were selected through random sampling. In the study, respondents were divided randomly into two groups: control and intervention groups. We exposed information regarding healthy diet and lifestyles through Instagram to the intervention group. All respondents were required to complete questionnaires on a healthy diet and eating habits.

There were two questionnaires used in this study to assess respondents' knowledge and behavioral changes: (1) healthy lifestyle, healthy diet, and eating habits knowledge questionnaire and (2) modified selfadministered food frequency questionnaire (FFQ). The first questionnaire was made based on previous studies [20]-[22]. It consisted of 44 questions and divided into four sections: (1) 7 questions of demographic data, (2) 6 questions regarding healthy lifestyle knowledge, (3) 23 questions regarding healthy diet practice, and (4) 15 questions regarding eating habits. Answers options were made based on the Likert Scale Scoring System, in which (1) stands for completely disagree; (2) disagree; (3) agree, and (4) agree. The second questionnaire was a modified self-administered Food Frequency Questionnaire based on previous studies [23]-[26]. Both questionnaires were tested for face validity among freshmen of both faculties. The selfadministered questionnaire successfully assessed healthy lifestyle, healthy diet, and eating habits knowledge and food frequency questionnaire for their overall eating habits.

The first questionnaire was administered before the campaign, while the rest was submitted once every month via Google form throughout the study duration. We notified and reminded respondents via chat 
messages. Quantitative data were analyzed descriptively. Data tabulation in frequencies depicted the trend and behavior towards students' respond regarding social media campaigns.

\subsection{Qualitative method}

The qualitative method design was an explorative study. To explore respondents' views towards the campaign, we selected fourteen respondents through purposeful sampling. There were twice interviews; (1) on the second month of the social media campaign and (2) on the fourth month of the social media campaign. The study was conducted for approximately four months, starting in February 2017. Qualitative data were collected using face-to-face interviews. We evaluated respondents' perspectives regarding the online campaign's effectiveness through approximately 10-15 minutes of an interview. All respondents received pins and pens as a token of appreciation for participating in the study. We utilized the constant comparative method (CCM) to analyze the qualitative data.

\section{RESULTS AND DISCUSSION}

\subsection{The knowledge acquisitions}

Respondents' knowledge was acquired from the first questionnaire about healthy lifestyle, healthy diet, and eating habits. Figure 1 shows the average score of the questionnaire was higher in intervention group. It increased from second month onwards, with an increment of at least $150 \%$. Figure 2 and 3 shows average correctly answered questions per section of the knowledge questionnaire. Within four months, a general increase of knowledge was observed, especially on the topic of healthy diet.

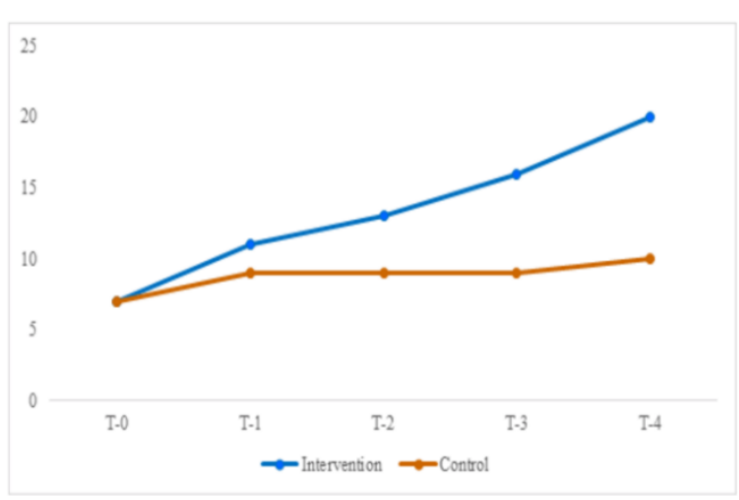

Figure 1. Average correctly answered questions among respondents in control and intervention group in monthly assessment

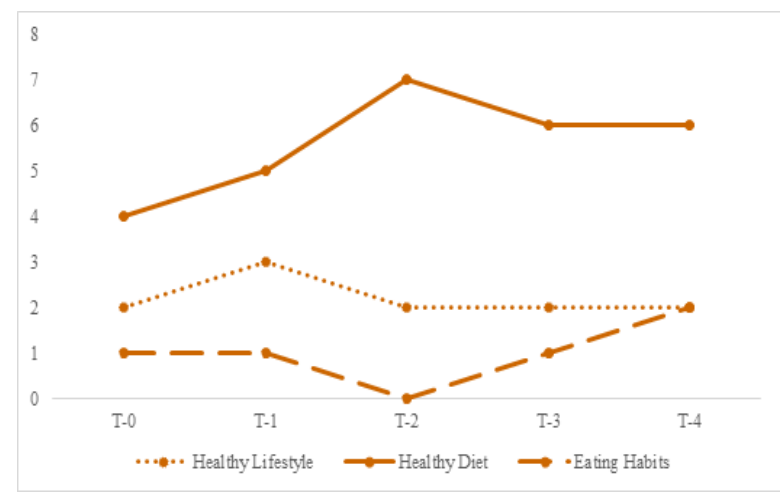

Figure 2. Control groups' monthly average score of healthy lifestyle, healthy diet and eating habit knowledge questionnaire $(n=69)$

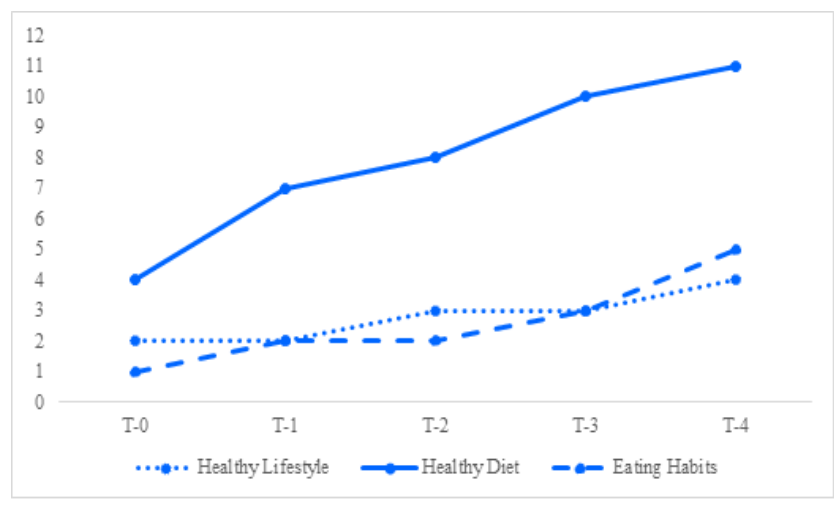

Figure 3. Intervention groups' monthly average score of the healthy lifestyle, healthy diet and eating habit knowledge questionnaire $(n=75)$ 


\subsection{Food frequency questionnaire (FFQ)}

Based on data acquired, respondents in both groups didn't show any meaningful changes in their daily consumption pattern. As seen from the Table 1, respondent did not include red rice and oatmeal in his daily dietary pattern despite knowing the health benefits it offers through Instagram post during campaign period. Coding table can be seen in Table 2.

Table 1. Part of food frequency questionnaire (FFQ), a typical respondents' response after campaign

\begin{tabular}{|c|c|c|c|c|c|c|c|c|}
\hline \multirow{2}{*}{$\begin{array}{c}\text { Food type and quantity } \\
\text { Cereal and similar } \\
\text { products } \\
\text { (medium serving) }\end{array}$} & \multicolumn{8}{|c|}{ Average Consumption per month (see notes) } \\
\hline & $\begin{array}{c}\text { Once a } \\
\text { week }\end{array}$ & $\begin{array}{c}2-4 \\
\text { times/week }\end{array}$ & $\begin{array}{c}5-6 \\
\text { times/week }\end{array}$ & $\begin{array}{c}\text { Once a } \\
\text { day }\end{array}$ & $\begin{array}{c}2-3 \\
\text { times/day }\end{array}$ & $\begin{array}{c}4-5 \\
\text { times/day }\end{array}$ & $\begin{array}{c}6+ \\
\text { times/day }\end{array}$ & $\begin{array}{l}\text { Never in a } \\
\text { month }\end{array}$ \\
\hline White rice & & & & & $\mathrm{v} \# *=^{\wedge}$ & & & \\
\hline Red rice & & & & & & & & $\mathrm{v} \# * *^{\wedge} \wedge$ \\
\hline Noodles & $\wedge$ & \#* & $\mathrm{v}=$ & & & & & \\
\hline Bread & & $\mathrm{v} \#=$ & & & & & & $* \wedge$ \\
\hline Oatmeal & & & & & & & & $\mathrm{v} \# *=\wedge$ \\
\hline Porridge & & & & & & & & $\mathrm{v} \# * *^{*} \wedge$ \\
\hline Corn flakes & & & & & & & & $\mathrm{v} \# * *^{\wedge} \wedge$ \\
\hline
\end{tabular}

Notes: $\mathrm{v}$ for $\mathrm{T} 0$; \# for $\mathrm{T} 1 ;{ }^{*}$ for $\mathrm{T} 2 ;=$ for $\mathrm{T} 3 ;{ }^{\wedge}$ for $\mathrm{T} 4$

Table 2. Coding table

\begin{tabular}{|c|c|c|}
\hline Categories & Coding & Definition \\
\hline \multirow{3}{*}{$\begin{array}{l}\text { Concept of } \\
\text { social media } \\
\text { campaign }\end{array}$} & $\begin{array}{c}\text { Frequency of } \\
\text { posting(s) }\end{array}$ & $\begin{array}{l}\text { The rate at which the campaign poster published and is repeated over a particular period of } \\
\text { time during intervention period is too little that it affects the outcome in a negative way. } \\
\text { Respondents' suggestion to publish fixed dates on questionnaire submission so they won't miss } \\
\text { it }\end{array}$ \\
\hline & Questionnaire(s) & $\begin{array}{l}\text { A set of written questions with a choice of answers, devised for the purpose of a survey or } \\
\text { statistical study that is used in the campaign and are easy to access and answer, adaptable to } \\
\text { circumstances that allow respondents to choose the time to submit them }\end{array}$ \\
\hline & Effectiveness & $\begin{array}{l}\text { The degree to which campaign is considered successful in enhancing knowledge regarding the } \\
\text { topics and encouraging daily habit changes from the beginning till the end of intervention period }\end{array}$ \\
\hline \multirow{2}{*}{$\begin{array}{l}\text { Campaign } \\
\text { Sketches }\end{array}$} & Interesting & Eye catching designs used in the campaign that triggers positive reactions from its readers \\
\hline & Boring & $\begin{array}{l}\text { Campaign's sketches, themes and colours failed to attract attention and/or gain interest from its } \\
\text { readers }\end{array}$ \\
\hline Message & Eating habit & $\begin{array}{l}\text { Campaign is easily seen and understood however this doesn't simply mean as implication on } \\
\text { daily lives by all respondents }\end{array}$ \\
\hline Suggestions & Promotion & $\begin{array}{l}\text { Respondents' suggestion to do more publications in order to increase public awareness of the } \\
\text { on-going intervention. Campaign to work with other group of people to increase public } \\
\text { awareness and interest of the on-going intervention. Campaign need to deliver facts and/or data } \\
\text { about healthy lifestyle, healthy diet and eating habits including the minor features. }\end{array}$ \\
\hline
\end{tabular}

\subsection{Concept of social media campaign}

Respondents found the campaign effective. Instagram was considered as a suitable tool to disseminate healthy lifestyle, healthy diet, and eating habits information. They did not mind answering questionnaires monthly as a measure of their understanding of the information provided. However, they expressed the need to post more than once a week to enhance campaign effectiveness.

"I want to continue participating. At first, I didn't know the answers to the given questions but as the time goes by, reading the uploaded post each week, being exposed to the given information once a week, I get to have better understanding. It's a good thing so I'm interested in following this campaign till the end." K1.1 // [394-717]

"Truth be told, it's enough because teenagers use Instagram, and the platform highlights picture more than the caption itself so it's more effective. They see the post, read, are curious and then learn about it. I feel it's better compared to other social media that has long captions." P2.1 // [79399-79811] 
Despite having unfamiliar terms used in the captions, participants found that a healthy lifestyle, healthy diet, and eating habits were easily understood. The information managed to motivate respondents to adopt a healthier kind of lifestyle and diet.

"I see ... I like the content and the topic because it highlights healthy lifestyle. Personally, I feel my lifestyle isn't that healthy so through this I feel more motivated to become healthier. But that's where it ends. Simply at having motivations, I haven't started any real-life changes so far." P1.5 // [43074-43360]

\subsubsection{Campaign sketches}

Illustrations and pictures in the campaign were eye-catching, diverse, and most likely to generate curiosity and attention. However, two main aspects could use some improvement. First, the campaign needed to have a distinctive design. Second, it could be improved by highlighting photos or changing ways of information distribution.

"I think, you see, a line on the feeds will showcase three pictures so maybe before the main post, you can give a sneak peek a day or two before. It can be a prolog or opening like for example nutrition. Instead of one, you can split if to separate post so people feel they gain more, the reaction will be better. Divided post is the better way, I think. " P1.6 // [146934-47353]

\subsubsection{Message}

Some respondents felt Bahasa Indonesia as a more suitable language to use in the campaign because it would prevent misunderstandings or misinterpretations. Furthermore, most respondents agreed that the extent of the information written in the description box was too long.

"Maybe it's better to do it in Bahasa Indonesia because it's easier to understand and might help people to get the idea without the trouble of translating it to Bahasa first." K1.1 // [78-243]

\subsubsection{Suggestions}

The main suggestion to gain more attention and better engagement is promotion. Direct promotion and working collaboratively across people or organizations were the best suggestion.

"I think promotion by more people is going to make the campaign better and more effective. I mean, this thing is like ... small right? So, if you want the information to be delivered to its targets, asking people to share it between their friends will be beneficial.” K1.2 // [10525-10801]

\subsection{Discussion}

This study has proven the effectiveness of Instagram campaign on healthy lifestyle, healthy diet, and eating habits through the knowledge acquisition and awareness of the issues. However, the intervention did not affect behavioral changes in eating habits. Figure 4 explains briefly how this research connected the knowledge acquisition and awareness of the issues. On the other part, the concept map showed that the investigation through FFQ and participants' interviews resulted in no behavior changes.

Prior studies have proven social media's effectiveness as a public educational tool [27], [28]. Health professionals also viewed social media as a useful platform to promote health issues [27], [29]. From the knowledge assessment of both groups, we found social media Instagram as a sufficient public health promotion platform. Moreover, it was perceived as the right choice for social media campaign. Moreover, participants expressed their appreciations towards the design, frequency of posting and questionnaires included in the posts during interview sessions. This all proved that the intervention was effective.

Leveraging on the impact and remarkable amplification power of social media applications nowadays, Instagram was perceived as the perfect place to promote and deliver health messages to public [29], [30]. Moreover, with its popularity and user-friendly features that enabled users to upload multiple pictures in on post, Instagram had successfully gained high engagement level of $70 \%$. This showed that respondents actively checked for updates on the app, explaining the positive outcome observed at the end of intervention period as shown in results.

Although there was a substantial increase in the number of questions answered correctly by participants in intervention groups, they have yet to answer all questions correctly. Theoretically, given their access to the information on Instagram, they should have been able to ace all questions. This fact suggested that there were other factors influencing the effectiveness of an online campaign other than choosing the right media to disseminate the information. Participants' feedbacks on the concept, captions, illustrations, and messages showed their refined suggestions toward the campaign. 


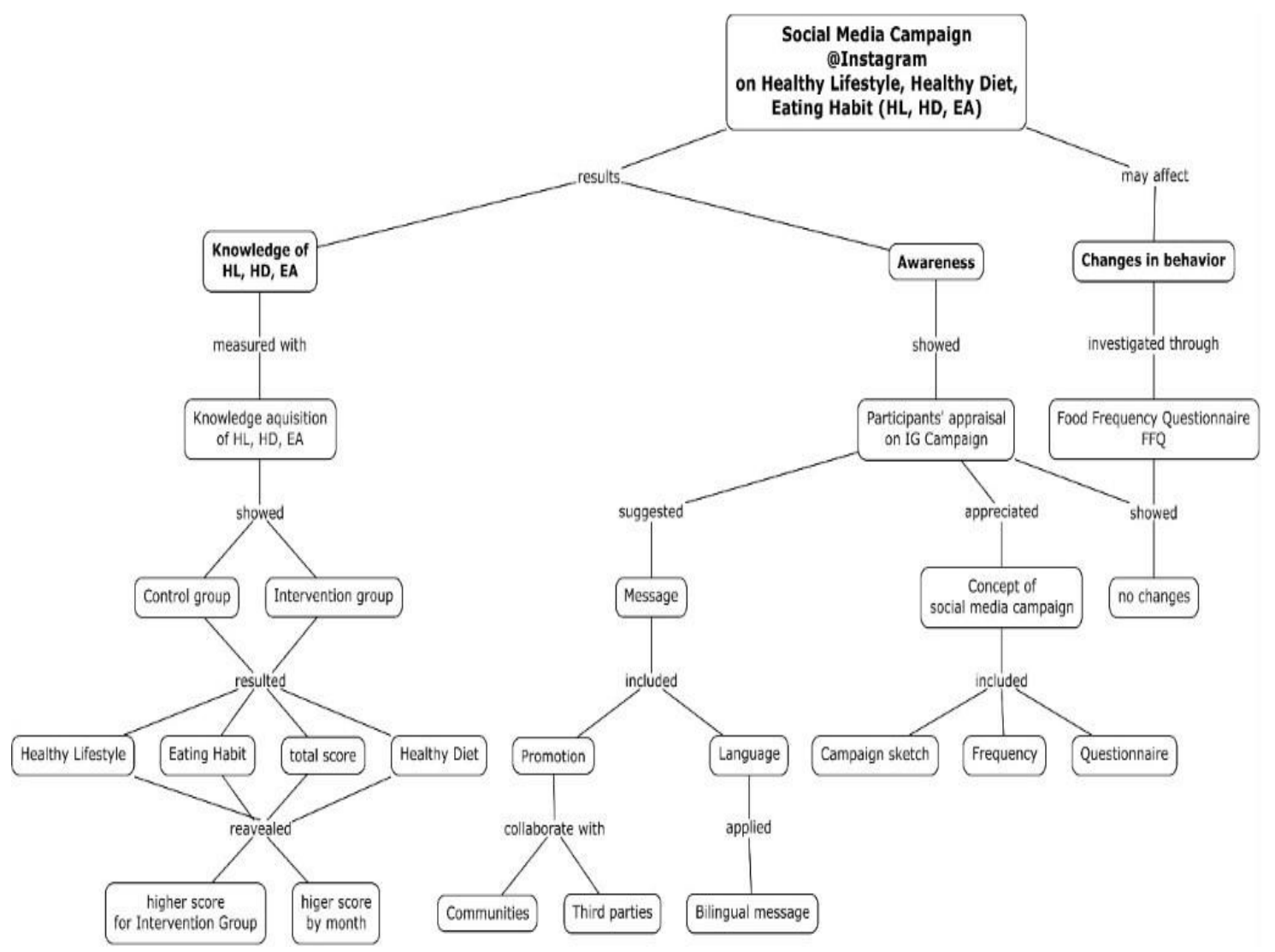

Figure 4. Concept map of research analysis

Another thing that could help is a video. Recent findings showed that videos would likely attract more attention from the viewers in the long run than posting photos only [18]. Videos are more likely to be perceived as exciting and worth sharing with their friends. It will be even better if participants could make videos, resulting in a more significant probability of sharing the video.

Using an eye-catching design with bright and bold colours on a straightforward background couple with enthralling yet easy to read fonts will also increase its effectiveness [30]. Moreover, working together with public figures or youth influencers may help gain more attention to the campaign [18]. This study's most important motive was information-seeking because respondents' curiosity will lead them to have better respond towards the given message that leads to a higher engagement level on this campaign [30]. Furthermore, having social media strategy and team to manage the overall campaign concept are crucial in ensuring better results as it continues to provide cohesive and high-quality resources for the targeted group [18]. Another factor that plays a role in the success of this intervention is frequency of posting. Previous study by Facebook Marketing Team found that higher frequency posting is required to generate impact, especially in promoting brand. Based on this finding, there were to ways to improve this campaign. First, conducting the campaign on the most visited social media platform by its readers. Second, more frequent postings, highlighting new simple and easy to understand messages.

These findings go along with the results gained from respondents' interviews in intervention groups. Most respondents suggested a more aggressive approach. It would be best to attract more viewers and enhance engagement level if there are two to three posts a week instead of one. Delivering the bilingual form information, having a distinctive design or signature Instagram theme with a better ratio between pictures and captions would also help. These suggestions seemed to be fitting and promising in enhancing the campaign's effectiveness.

This study also aimed to assess the behavioural changes towards adopting healthier diet and eating habits. Unfortunately, there were no meaningful changes, indicating other factors influencing one's decision to change their dietary habits despite having adequate knowledge. A previous study [31] identified three main factors that took parts in determining one's ability to adopt healthy diet and eating habits. Those three are food environment, individual preferences, and religious influences [31]. Food environment is a term that encompasses both food access and food availability. If there are sufficient resources to obtain nutritious, 
healthy food, people are more likely to adopt a healthier dietary pattern. Another factor is the respondents' personal preference to taste. The problem of eating healthier is that lots of healthier food ingredients are deemed unfavourable in terms of taste, partially because it might not be a staple in the list of food people consume since young. Given that most people still prioritize taste over health benefits, they will be more likely to continue consuming foods that taste better to their taste buds. Moreover, religious concerns and cultural backgrounds also might influence people from consuming certain food ingredients [31].

Specific to this study, this campaign's ineffectiveness in influencing behavioural change was caused mainly by two factors: time constraint and affordability of healthy food items. During interviews, participants had directly mentioned time constraints as a barrier to adopting a healthier lifestyle. They were featured as super fans of the Instagram account as outlined in the Instagram evaluation report. Students were bound with hectic and demanding schedules all week long, while a healthy diet and eating habits demand quite some time, from food preparation to cooking time, which respondents do not have given to their schedules. For students living in dorms, it is time wise to purchase ready to eat meals outside. Other than that, some might not have access to proper kitchen wares either. Students living with their parents do not have much say to what menu is served at home daily, making it harder to change their eating pattern immediately, regardless of having adequate knowledge of a healthy diet. Another critical factor mentioned during interviews was the affordability and availability of healthy food items. Healthy meal options or food items are not readily available in cafeterias or canteens frequently visited by the respondents of this study, causing them to purchase whatever was available. Furthermore, most students cannot afford it since they are pricy.

This study's limitation was in the usage of FFQ to assess eating habits before and after the intervention. FFQ was too long as a self-questionnaire. Real-time reports using photos or videos will be more straightforward for college students to reveal what they eat-in this matter, incorporating more visual qualitative data. Assessment of participants' food intake will reveal the eating habit.

\subsection{Limitations}

The campaign was exclusively carried through Instagram, assuming every participant within the intervention group had an active Instagram account and adequate usage during intervention period. Observed differences amongst participants were solely attributed to the chosen intervention method despite the possibility of being exposed to other sources of information as well.

\section{CONCLUSION}

Healthy lifestyle, healthy diet, and eating habits promotion using Instagram have been proven successful and effective in enhancing awareness and raising overall knowledge regarding the topics. However, it did not lead to changes in daily dietary patterns among respondents, suggesting there were more than one-factor that influenced food choices in daily lives. The online campaign was perceived well by respondents in intervention groups despite needing improvements to gain better engagement throughout intervention period. Social media was perceived as a useful educational tool about healthy lifestyle, healthy diet, and eating habits toward college students. Collaboration among health professionals, communicators, influencers, and communities will be valuable. The message will spread out widely through collaboration. Communities related to the issues will bring up the discussion; in return, it may improve eating habits. Changes in behaviour in a healthy diet may need the availability and affordability of healthy food for college students. Concerns regarding these issues would relate to the supply chain of healthy food. Therefore, both policy and practice toward availability and affordability play a crucial part in people eating habits. Research toward social media as health-related education needs a continuous assessment bound to the information provided. This study revealed that further collaboration might change not only on the information provided but also on healthy diet behavior.

\section{ACKNOWLEDGEMENTS}

We acknowledged the Dean of the School of Medicine and Health Sciences for this study's support, participants of this study, and Medical Education Unit members for continuous support

\section{REFERENCES}

[1] Bakker M, "Joint programming initiative a healthy diet for a healthy life," Annals of Nutrition and Metabolism, no. 67, 2015.

[2] Nielsen. N, "We are what we eat: Healthy eating trends around the world," The Nielsen Company: Global Health and Wellness Report, pp. 1-17, 2015. 
[3] Alkerwi A., Sauvageot N., Malan L., Shivappa N., and Hébert J. R.., “Association between nutritional awareness and diet quality: Evidence from the observation of cardiovascular risk factors in Luxembourg (ORISCAV-LUX) study," Nutrients, vol. 7, no. 4, pp. 2823-2838, 2015.

[4] Oddo V, Maehara M, and Rah J, "Overweight in Indonesia: An observational study of trends and risk factors among adults and children," BMJ Open, vol. 9, no. 9, pp. 1-14, 2019, doi: 10.1136/bmjopen-2019-031198.

[5] Gray C. L., Messer L. C., Rappazzo K. M., Jagai J. S., Grabich S. C., and Lobdell D. T, "The association between physical inactivity and obesity is modified by five domains of environmental quality in U.S. adults: A crosssectional study," PLOS ONE, vol. 13, no. 8, pp. 1-14, 2018, doi: 10.1371/journal.pone.0203301.

[6] Wright N., Wilson L., Smith M., Duncan B., and McHugh P, "The BROAD study: A randomised controlled trial using a whole food plant-based diet in the community for obesity, ischaemic heart disease or diabetes," Nutrition and Diabetes, vol. 7, no. 3, pp. 1-10, 2017.

[7] Crouter S. E, Hibbing P. R, and LaMunion S. R, "Use of objective measures to estimate sedentary time in youth," Journal for the Measurement of Physical Behaviour, vol. 1, no. 3, pp. 136-142, 2018.

[8] Goff L. M, "Ethnicity and type 2 diabetes in the UK," Diabetic Medicine, vol. 36, no. 8, pp. 927-938, 2019.

[9] Hills A. P et al., "Epidemiology and determinants of type 2 diabetes in south Asia," The Lancet Diabetes and Endocrinology, vol. 6, no. 12, pp. 966-978, 2018.

[10] Misra A., Gopalan H., Jayawardena R., Hills A. P., Soares M., Reza-Albarrán A. A., and Ramaiya K. L, "Diabetes in developing countries," Journal of Diabetes, vol. 11, no. 7, pp. 522-539, 2019.

[11] Katz D. L., Frates E. P., Bonnet J. P., Gupta S. K., Vartiainen E., and Carmona R. H, "Lifestyle as medicine: The case for a true health initiative," American Journal of Health Promotion, vol. 32, no. 6, pp. 1452-1458, 2018.

[12] González-Gil. E. M et al., "Healthy eating determinants and dietary patterns in European adolescents: The HELENA study," Child and Adolescent Obesity, vol. 2, no. 1, pp. 18-39, 2019.

[13] Haq I. U et al., "Identification of body composition, dietary patterns and its associated factors in medical university students in China," Ecology of Food and Nutrition, vol. 59, no. 1, pp. 65-78, 2020.

[14] Yahia N et al., "Assessment of weight status, dietary habits and beliefs, physical activity, and nutritional knowledge among university students," Perspectives in Public Health, vol. 136, no. 4, pp. 231-244, 2016.

[15] Voinea L et al., Research on food behavior in romania from the perspective of supporting healthy eating habits, Sustainability; Basel, vol. 11, no. 19, pp. 5255, 2019.

[16] Lambert M, Chivers. P, and Farringdon F, "In their own words: A qualitative study exploring influences on the food choices of university students," Health Promotion Journal of Australia; Milton, vol. 30, no. 1, pp. 66-75, 2019.

[17] Finnell K. J and John R "A social marketing approach to $1 \%$ milk use: Resonance is the key," Health Promotion Practice, vol. 19, no. 3, pp. 437-444, 2017.

[18] Kite J., McGill B., Freeman B., Vineburg J., Li V., Berton N., and Grunseit A, "User perceptions of the make healthy normal campaign Facebook Page: A mixed methods study," Social Media + Society, vol. 4, no. 3, pp. 1-17, 2018.

[19] Raggatt M., Wright C. J., Carrotte E., Jenkinson R., Mulgrew K., Prichard I., and Lim, M. S, "I aspire to look and feel healthy like the posts convey: engagement with fitness inspiration on social media and perceptions of its influence on health and wellbeing," BMC Public Health, vol. 18, no. 1, pp. 1-11, 2018.

[20] Banna J. C., Gilliland B., Keefe M., and Zheng D. "Cross-cultural comparison of perspectives on healthy eating among Chinese and American undergraduate students," BMC Public Health; London, vol. 16, no. 1, pp. 1-12, 2016.

[21] Bully P et al., "Metric properties of the "prescribe healthy life" screening questionnaire to detect healthy behaviors: A cross-sectional pilot study," BMC Public Health; London, vol. 16, no. 1, pp. 1-11, 2016.

[22] Mötteli S., Keller C., Siegrist M., Barbey J., and Bucher, T, "Consumers' practical understanding of healthy food choices: A fake food experiment,” The British Journal of Nutrition; Cambridge, vol. 116, no. 3, pp. 559-566, 2016.

[23] El Kinany K et al., "Adaptation and validation of a food frequency questionnaire (FFQ) to assess dietary intake in Moroccan adults," Nutrition Journal, vol. 17, no. 1, pp. 1-12, 2018.

[24] Rodríguez M. G., Saldaña M. R., Leyva J. M. A., Rojas R. M., and Recio, G. M, "Design and validation of a food frequency questionnaire (FFQ) for the nutritional evaluation of food intake in the Peruvian Amazon," Journal of Health, Population and Nutrition, vol. 38, no. 1, pp. 1-11, 2019.

[25] Kotemori A et al., "Validity of a self-administered food frequency questionnaire for the estimation of acrylamide intake in the Japanese population: The JPHC FFQ Validation Study," Journal of Epidemiology, vol. 28, no. 12, pp. 482-487, 2018.

[26] Kaur S et al., "Validation and reproducibility of a culturally specific food frequency questionnaire (FFQ) for Malaysian Punjabis," Malaysian Journal of Nutrition, vol. 22, no. 2, pp. 245-255, 2016.

[27] Bannor. R, Asare. A. K, and Bawole. J. N, "Effectiveness of social media for communicating health messages in Ghana," Health Education; Bradford, vol. 117, no. 4, pp. 342-371, 2017.

[28] Xiao-Ling. J, Zhou. Z, and Yu. X, "Predicting Users' willingness to diffuse healthcare knowledge in social media," Information Technology and People; West Linn, vol. 32, no. 4, pp. 1044-1064, 2019.

[29] Latha K., Meena K. S., Pravitha M. R., Dasgupta M., and Chaturvedi, S. K, "Effective use of social media platforms for promotion of mental health awareness," Journal of Education and Health Promotion; Mumbai, vol. 9 , no. 1, pp. 1-11, 2020.

[30] Riesmeyer C, Hauswald J, and Mergen M, “(Un)healthy behavior? The relationship between media literacy, nutritional behavior, and self-representation on Instagram," Media and Communication; Lisbon, vol. 7, no. 2, pp. 160-168. 2019.

[31] Alakaam A. A et al., "The factors that influence dietary habits among international students in the United States," Journal of International Students, vol. 5, no. 2, pp. 104-120, 2015. 